\section{Growth, Physiological Response, and Quality Characteristics of Weeping Fig in Response to Shading Levels and Climatic Conditions}

\author{
Domenica Scuderi, Francesco Giuffrida ${ }^{1}$, Stefania Toscano, \\ and Daniela Romano \\ Department of Agricultural and Food Science, University of Catania, \\ Via Valdisavoia 5, 95123 Catania, Italy
}

Additional index words. Ficus benjamina, irradiance, photosynthetic light response, canopy architecture, ornamental value

\begin{abstract}
The aim of this study was to evaluate the effects of light availability and the climatic conditions on the growth and quality of weeping fig (Ficus benjamina $\mathbf{L}$.). Plants of cv. Danielle were grown under five shading conditions $(0 \%, 20 \%, 40 \%, 60 \%$, and $80 \%$ reduction of the incident irradiance inside the greenhouse) and two cultivation periods (from May to October and from December to May). The light intensity in no shading treatment ranged from 6.3 to $16.4 \mathrm{MJ} \cdot \mathrm{m}^{-2} \cdot \mathrm{d}^{-1}$ in May to October and from 4.6 to 14.5 $\mathrm{MJ} \cdot \mathrm{m}^{-2} \cdot \mathrm{d}^{-1}$ in December to May. Depending on climatic conditions, the light reduction resulting from shading produced strong differences in the growth of weeping fig. With increasing shading, the dry weight decreased from 282.4 to $113.3 \mathrm{~g} / \mathrm{plant}$ during the first growth period, which was the period characterized by the highest values of global radiation and temperature, and from 120.8 to $56.8 \mathrm{~g} / \mathrm{plant}$ during the second period. The effects of reduced light were evident in the plant quality, which is associated with the canopy and leaf characteristics. In particular, as a result of the increase of the apparent quantum yield and reduction of light compensation point, the most shaded plants showed a photosynthetic advantage over the control $(0 \%)$ at a low irradiance level. Increased shading caused a reduction of plant compactness because of the increase of the internode length and branch insertion angle. Although shading also resulted in a reduction in the leaf number, the plant ornamental value was unaffected because of the highest unit leaf area $(+72 \%)$ in both of the growth periods. Based on our results, the greatest decrease in irradiance $(60 \%$ and $80 \%$ of shading) reduced the plant growth and compactness more in the growth period characterized by the highest values of global radiation and temperature, whereas the quality of the plants was improved by shading in both of the growth periods.
\end{abstract}

Ornamental foliage plants used for interior decoration are able to grow under an indoor environment because of a native adaptation to conditions of low light. During the cultivation of these plants, a reduction of light availability is imposed to improve the acclimatization to the final destination use and to modify the ornamental value of the plants (Chen et al., 2005a).

Previous studies on the response of ornamental plants to low light conditions showed important modifications of the following morphophysiological parameters: variation in the biomass partitioning between shoots and roots (Veneklaas and Poorter, 1998); changes in the photosynthetic response (Fails et al., 1982b;

\footnotetext{
Received for publication 18 July 2012. Accepted for publication 4 Sept. 2012.

This research was supported by Ministry of Education, University and Research (MIUR), PRIN Project 2007 "Post-production physiology of ornamentals and quality maintenance technologies" (Coordinator Prof. S. De Pascale).

${ }^{1}$ To whom reprint requests should be addressed; e-mail francesco.giuffrida@unict.it.
}

Miralles et al., 2011) through a modification of the daily photosynthetic response curves (Lambers et al., 1998); and changes of the leaf area per unit of dry weight through modifications in the foliar anatomy (Fails et al., 1982a; Vats et al., 2002). A frequent variation that results from low light availability is thinner leaves with a greater leaf area (Niinemets, 2010) and a dark green color as a result of the increased chlorophyll content (Chen et al., 2005b; Fails et al., 1982a). Sawwan and Ghunem (1999) found that Schefflera arboricola increased the photosynthetic surface with a low light level, and this result was related to a better performance of the plants in a simulated interior environment. Moreover, plants may modify their canopy architecture, thus adjusting the capacity to intercept light (Knapp and Smith, 1997; Valladares and Pearcy, 2000).

Certain plant modifications resulting from the adaptation to low light conditions could influence the appearance of the plant and therefore the quality attributes. Indeed, DijkshoornDekker (2002) and Heuvelink et al. (2004) proposed to use the width, shape, or density of the plant to define the visual quality of the product. Miralles et al. (2011) found that Rhamnus alaternus plants grown under low light conditions showed a less compact canopy with longer internodes than unshaded plants.

Weeping fig (Ficus benjamina L.) is one of the most popular ornamental foliage plants, and it is indigenous to the tropical and subtropical regions of South Asia. As a result of its ability to adapt to low light conditions, $F$. benjamina is largely used for decorating indoor environments, and numerous studies have been conducted examining the effect of low light on this species (Conover and Poole, 1990; Kubatsch et al., 2005; Sarracino et al., 1992). However, the morphophysiological modifications resulting from the light availability during the production period have mainly been considered to evaluate the potential indoor acclimatization of the plants (Fails et al., 1982b; Mortensen, 1992b; Sarracino et al., 1992). Thus, the influence of these plant modifications on the qualitative evaluation of weeping fig was underinvestigated.

Although certain plant modifications resulting from low light during cultivation could improve the quality characteristics (e.g., a large surface area and dark green color of the leaves) and acclimatization to low light environments, such shading conditions limit the daily production of matter (Cannell et al., 1987), and thus the production period is extended (Veneklaas et al., 2002; Yeh and Wang, 2000). Previous experiments on the effects of light availability on weeping fig showed a significant reduction in plant growth at diminished light levels; however, these results are often not comparable owing to the different climatic conditions during the experiment (Fails et al., 1982a; Sarracino et al., 1992; Scuderi et al., 2008).

Within the context of these considerations, an evaluation of the potential interaction effects of shading with the climate is important because the widespread cultivation cycle of this ornamental foliage plant in the Mediterranean region is approximately six months with different thermoradiative growth conditions being intercepted during the year. Therefore, the aim of this study was to evaluate the effects of the shading conditions on the growth and morphological, anatomical, and physiological characteristics related to the quality of weeping fig grown during two growth periods characterized by different climatic conditions.

\section{Materials and Methods}

Plant material, treatments, and growth conditions. The experimental trials were conducted in a cold greenhouse in Catania (South of Italy, lat. $37^{\circ} 30^{\prime} \mathrm{N}$, long. $15^{\circ} 06^{\prime} \mathrm{E}$, $20 \mathrm{~m}$ a.s.1.) using plants of Ficus benjamina L. 'Danielle'.

The treatments were defined by a factorial combination of five shading levels $(0 \%, 20 \%$, $40 \%, 60 \%$, and $80 \%$ reduction of the incident irradiance inside the greenhouse) and two growth periods, specifically, from May to October (GP I) and from December to May 
(GP II). The light intensity in no shading treatment ranged from 6.3 to $16.4 \mathrm{MJ} \cdot \mathrm{m}^{-2} \cdot \mathrm{d}^{-1}$ in GP I and from 4.6 to $14.5 \mathrm{MJ} \cdot \mathrm{m}^{-2} \cdot \mathrm{d}^{-1}$ in GP II. The experiment was conducted as a randomized complete block design with three replications per treatment; each experimental unit consisted of 20 plants.

In each growth period, one-month-old plants (total dry weight of $25.45 \pm 2.7$ and $21.40 \pm 1.2 \mathrm{~g}$, respectively, for GP I and GP II) were grown into $16-\mathrm{cm}$ plastic pots $\left(3000 \mathrm{~cm}^{3}\right)$ with a substrate of a one peat:one perlite ratio (by volume). The pots were arranged at a density of 7.1 pots $/ \mathrm{m}^{2}$ (40 $\mathrm{cm}$ between the rows and $35 \mathrm{~cm}$ within the row). The pots were placed under different shading nylon nets that were placed on a wooden frame $200 \mathrm{~cm}$ high off the ground, and the lateral sides were covered to $40 \mathrm{~cm}$ from the bottom to improve the ventilation; the $0 \%$ grown plants had no shading nets (control). During the experiments, the plants were fertilized every 2 weeks with a $20 \mathrm{~N}-8.6 \mathrm{P}-16.6 \mathrm{~K}$ water-soluble fertilizer (Agrisol NPK 20-20-20; Agrisol, Ravenna, Italy) at $2 \mathrm{~g}$ per pot. Plants were watered according to the microclimatic conditions and the substrate moisture status. Water was supplied to the plants to maintain a soil moisture at pot capacity.

The mean air temperature, relative humidity, and global radiation under the different shading conditions were recorded using a data logger CR1000 (Campbell Scientific Ltd., Loughborough, U.K.) during the experimental periods. Probes were set at the plant tips in the center of one block for each shading treatment.

The reduction in the irradiation level determined by the nets did not consistently correspond to the characteristics provided by the supplier company. The real shading percentages for each treatment were $15.2 \% \pm$ $0.6 \%, 39.2 \% \pm 0.3 \%, 60.2 \% \pm 0.6 \%$, and $85.2 \% \pm 0.2 \%$ for the $20 \%, 40 \%, 60 \%$, and $80 \%$ shading nets, respectively. The trend of the global radiation during the two growth periods is reported in Figure 1. The mean temperature recorded in the control (unshaded) during GP I and GP II was 24.9 and $17.4{ }^{\circ} \mathrm{C}$, respectively, and the relative humidity was $67.1 \%$ and $75.2 \%$, respectively. Regardless, the differences among the shading conditions for each growth period were always less than $2{ }^{\circ} \mathrm{C}$ for the temperature and $10 \%$ for the relative humidity.

Biomass production and plant characteristics. At the end of each growth period, the plants located at the borders were excluded, and nine pots per treatment (three per replication) were randomly chosen to measure the following parameters: the dry weight production and partitioning, canopy characteristics (internode length, stem diameter, secondary branch insertion angle, and leaf number), and leaf characteristics (unit area, specific leaf area, lamina angle and bend, chlorophyll content, and mesophyll structure).

The dry weight (DW) was obtained by drying weighed samples in a thermoventilated oven at $70{ }^{\circ} \mathrm{C}$ to a constant weight.

The shoot length was measured and divided by the number of nodes to determine the average internode length, and the stem diameter was measured $1 \mathrm{~cm}$ above the substrate level.

The angle of insertion on the main stem of the secondary branch was measured using a protractor. The same was used to measure the angle of the leaf of a previously cut crosssection of the lamina. The lamina bend was determined by the measurement of the radius of the circle, which better fit with the projection of the leaf cut lengthwise on a horizontal plane. The lamina angle and bend were determined from a random sample of 10 leaves per pot. The leaf area was determined using a leaf area meter (Delta-T Devices Ltd., Cambridge, U.K.).

The chlorophyll content was determined using a SPAD-502 chlorophyll meter (Minolta Camera Co., Osaka, Japan). As proposed by Wang et al. (2005), a calibration curve was plotted considering the relationship between the SPAD values and the chlorophyll content as extracted according to Moran and Porath (1980). The following equation was used to obtain the chlorophyll content $\left(\mu \mathrm{g} \cdot \mathrm{cm}^{-2}\right)$ : chlorophyll $\left(\mu \mathrm{g} \cdot \mathrm{cm}^{-2}\right)=0.0231(\mathrm{SPAD}$ in$\operatorname{dex})^{2}-1.2789($ SPAD index $)+35.803\left(R^{2}=\right.$ $\left.0.9258^{* * *}\right)(\mathrm{n}=25)$.

The anatomical study of the leaf crosssections was performed by embedding the samples in cold-polymerizing resin (Tecnovit 7100; Heraeus Kulzer GmbH \& CO. KG, Hanau, Germany). Leaf sections 4 to $6 \mu \mathrm{m}$ thick were prepared using a rotary microtome (Leica Microsystems GmbH, Wetzlar, Germany), placed on glass slides, and analyzed using an image analyzer (Leitz Model ASM 68K; Hexagon Metrology $\mathrm{GmbH})$.

Photosynthesis measurements. During the last week of each growth period, the gas exchange was measured with a $\mathrm{CO}_{2} / \mathrm{H}_{2} \mathrm{O}$ IR gas analyzer (LCi; ADC Bioscientific Ltd., Hoddesdon, U.K.) using four plants per replication. The measurements were performed in

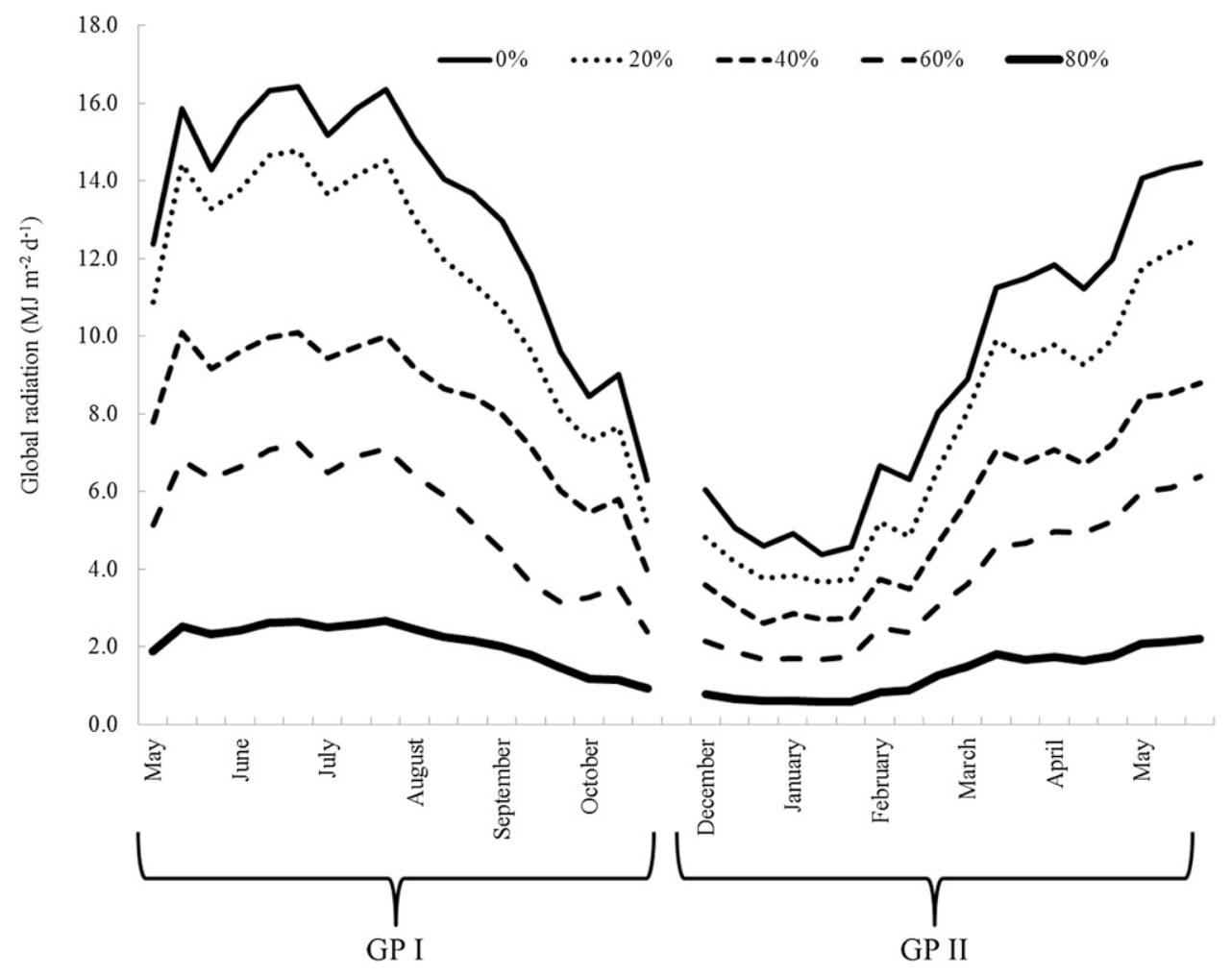

Fig. 1. Global radiation during the two growth periods under the different shading conditions. 
clear weather conditions from $0900 \mathrm{HR}$ to $1200 \mathrm{HR}$, and the net photosynthetic rate $\left(\mathrm{P}_{\mathrm{n}}\right)$, stomatal conductance $\left(g_{\mathrm{S}}\right)$, and intercellular $\mathrm{CO}_{2}$ concentration $\left(\mathrm{C}_{\mathrm{i}}\right)$ were obtained under light conditions determined by each shade treatment. All of the photosynthesis measurements were performed on outer fully expanded leaves sampled on branches located in the middle of the canopy.

The light-response curve measurements were performed from $0830 \mathrm{HR}$ to $1200 \mathrm{HR}$. The $\mathrm{CO}_{2}$ and air temperature in the leaf chamber were maintained at $\approx 380 \mu \mathrm{mol} \cdot \mathrm{mol}^{-1}$ and $25^{\circ} \mathrm{C}$, respectively. Six irradiance levels were arranged using shading screens to produce reductions of $0 \%, 20 \%, 40 \%, 60 \%$, $80 \%$, and $99 \%$ of the incident irradiance in the leaf chamber. The measurements started at $0 \%$ of shading and decreased stepwise to 99\%. The leaves were allowed to acclimatize to each shading level, and the steady-state gas exchange properties were observed and logged; subsequently, the shade screen above the leaf chamber was changed. Light-response curves were determined for six pots (two per replication) at each shading level. Over the $7 \mathrm{~d}$ during which the gas exchange measurements were obtained, the ambient $\mathrm{CO}_{2}$ levels ranged from 360 to $380 \mathrm{ppm}$, and the ambient relative humidity ranged from $60 \%$ to $75 \%$ in the greenhouse.

The photosynthetic light-response functions were formulated based on the Mitscherlich model equation proposed by Peek et al. (2002):

$$
\mathrm{P}_{\mathrm{n}}=\mathrm{A}_{\max }\left[1-\mathrm{e}^{-\mathrm{Aqe}(\mathrm{PPF}-\mathrm{LCP})}\right]
$$

From these functions, the following parameters were estimated: $A_{\max }$, the lightsaturated rate of photosynthesis, which represents the asymptote of photosynthesis at high light; $A_{q e}$, the apparent quantum yield, which corresponds to the initial slope of the curve at low light levels; and $L C P$, the light compensation point, which denotes the $\mathrm{x}$-intercept when the net photosynthesis is equal to zero. $P P F$ refers to the incident photosynthetic photon flux.

The quantum yield of PSII was measured using the light-adapted test of the modulated chlorophyll fluorometer OS1-FL (OptiSciences Corporation, Tyngsboro, MA). With this system, the chlorophyll fluorescence is excited by a $660 \mathrm{~nm}$ solid-state light source with filters blocking the radiation longer than $690 \mathrm{~nm}$. The average intensity of this modulated light was adjusted from 0 to $1 \mu \mathrm{E}$. The detection was in the 700- to 750-nm range using a PIN silicon photodiode with appropriate filtering to remove the extraneous light. The saturation of the photosystem being measured was provided by a filtered $35-\mathrm{W}$ halogen lamp (350 to $690 \mathrm{~nm}$ ). Each leaf was dark-adapted using cuvette clips supplied by the company for 20 min according to Camejo et al. (2005). The fluorescence was expressed as the $\mathrm{F}_{\mathrm{v}} / \mathrm{F}_{\mathrm{m}}$ ratio, which indicates the maximal quantum yield of PSII photochemistry, where $F_{m}=$ the maximal fluorescence of the dark-adapted state and
$\mathrm{F}_{\mathrm{v}}=$ the variable fluorescence (Schreiber et al., 1986).

Statistical analysis. A two-way fixedeffects general linear model analysis of variance (ANOVA) was used to determine the effects of shading and the growth period on the morphophysiological characteristics of the weeping fig plants. Simple regression models were adopted to determine the linear and quadratic relationships between shading and each considered variable. For each variable, the simplest significant regression is reported and discussed. An $\alpha$ level of 0.05 was selected for the ANOVA. The statistical analyses were performed using CoStat release 6.311 (CoHort Software, Monterey, CA). The interactions, when significant, are presented separately in the figures.

\section{Results}

Biomass production and partitioning. The increase in the shading level caused a linear decrease in the total DW production; however, significant differences in this trend were recorded depending on the growth period (Fig. 2A). During GP I, the total dry weight decreased from 282.4 to $113.3 \mathrm{~g} /$ plant with a relative reduction of $\approx 60 \%$, whereas this reduction was less accentuated $(-53 \%)$ in GP II. The shading determined a different dry weight partitioning with a more evident reduction of the root DW than the shoot DW. Furthermore, the effect of shading on the root DW was dependent on the growth period with a more evident decrease during GP I (Fig. 2B). These results caused an increase in the shoot-to-root ratio, starting from the $40 \%$ shading level during GP I, whereas no differences were observed for GP II (Fig. 2C).
Leaf photosynthetic characteristics. During the photosynthesis measurements under the experimental light conditions, the $P P F$ ranged at the $0 \%$ and $80 \%$ shading levels from 880 to $142 \mu \mathrm{mol} \cdot \mathrm{m}^{-2} \cdot \mathrm{s}^{-1}$ in GP I and from 1531 to $173 \mu \mathrm{mol} \cdot \mathrm{m}^{-2} \cdot \mathrm{s}^{-1}$ in GP II. The $\mathrm{P}_{\mathrm{n}}$ showed a linear decrease related to the shading level from $8.35 \mu \mathrm{mol} \mathrm{CO} / \mathrm{m}^{2} / \mathrm{s}$ of the control to $4.74 \mu \mathrm{mol} \mathrm{CO} 2 / \mathrm{m}^{2} / \mathrm{s}$ of the $80 \%$ shaded plants with a reduction of $43 \%$ for the mean of the two growth periods (Table 1). In relation to the cultivation cycle, the plants showed higher $\mathrm{P}_{\mathrm{n}}$ values in GP II (Table 1). In contrast, the $g_{\mathrm{S}}$ was unaffected by the light conditions and the growth period (Table 1). The $C_{i}$ showed a significant positive linear relationship with the shading level but was unaffected by the growth period (Table 1). In addition, the chlorophyll fluorescence $\left(\mathrm{F}_{\mathrm{v}} / \mathrm{F}_{\mathrm{m}}\right)$ was not modified by the climatic conditions of the cultivation cycle, although a significant increase from 0.74 for the control to 0.82 for the $80 \%$ shaded plants was recorded (Table 1).

The plant response to light curves showed that the saturation occurred at a lower photosynthetically active radiation in GP I than GP II (Fig. 3A-B). The plants at $80 \%$ shading exhibited a higher net assimilation at the lower light conditions in GP II than the other treatments. The light-response curve coefficients were significantly affected by the shading level. The $A_{\max }$ decreased linearly with the increase of shading and, with regard to significant interaction effects, this reduction was more accentuated in the plants grown during GP I (Fig. 4). The apparent quantum yield $\left(A_{q e}\right)$ was affected by the shading levels with a linear increase related to the light reduction (Table 1); the values of this coefficient
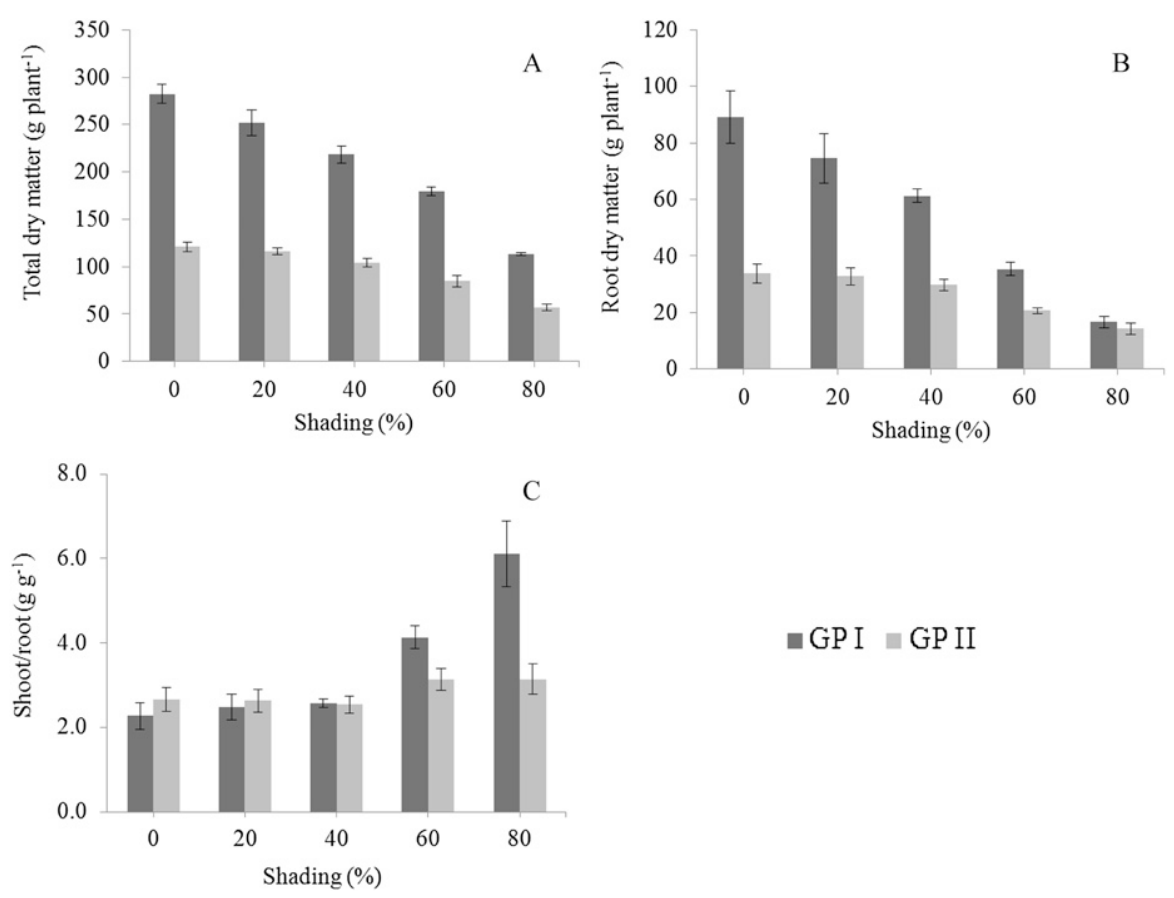

Fig. 2. Interaction effects of the shading level and growth period on the total dry weight (A), root dry weight $(\mathbf{B})$, and shoot-to-root ratio $(\mathbf{C})$. The vertical bars indicate $\pm \mathrm{SE}$ of the mean $(\mathrm{n}=3)$. 
Table 1. Mean effects of the shading level and growth period on the gas exchange parameters, chlorophyll fluorescence, and photosynthetic light-response curve coefficients of weeping fig plants. ${ }^{z}$

\begin{tabular}{|c|c|c|c|c|c|c|}
\hline Treatments & $\mathrm{P}_{\mathrm{n}}\left(\mu \mathrm{mol} \mathrm{CO} \mathrm{CO}_{2} / \mathrm{m}^{2} / \mathrm{s}\right)$ & $g_{\mathrm{S}}\left(\mathrm{mol} \mathrm{H} \mathrm{H}_{2} \mathrm{O} \mathrm{m}^{2} / \mathrm{s}\right)$ & $\mathrm{C}_{\mathrm{i}}\left(\mathrm{cm}^{3} \cdot \mathrm{m}^{-3}\right)$ & $\mathrm{F}_{\mathrm{v}} / \mathrm{F}_{\mathrm{m}}$ & $A_{q e^{\mathrm{y}}}$ & $L C P^{\mathrm{y}}$ \\
\hline \multicolumn{7}{|l|}{ Shading } \\
\hline $20 \%$ & $7.13 \pm 0.50$ & $0.10 \pm 0.02$ & $207 \pm 4.7$ & $0.77 \pm 0.01$ & $0.0029 \pm 0.0003$ & $17.70 \pm 2.20$ \\
\hline $40 \%$ & $7.02 \pm 0.59$ & $0.10 \pm 0.01$ & $221 \pm 11.5$ & $0.78 \pm 0.01$ & $0.0036 \pm 0.0006$ & $11.69 \pm 2.18$ \\
\hline $80 \%$ & $4.74 \pm 0.20$ & $0.09 \pm 0.01$ & $252 \pm 16.8$ & $0.82 \pm 0.01$ & $0.0078 \pm 0.0009$ & $5.89 \pm 1.06$ \\
\hline \multicolumn{7}{|l|}{ Growth period } \\
\hline I & $5.87 \pm 0.32$ & $0.09 \pm 0.01$ & $229 \pm 14.6$ & $0.78 \pm 0.01$ & $0.0047 \pm 0.0006$ & $14.60 \pm 4.23$ \\
\hline Shading & $\mathrm{L}^{* * *}$ & NS & $\mathrm{L}^{*}$ & $\mathrm{~L}^{* *}$ & $\mathrm{~L}^{* * *}$ & $\mathrm{~L}^{*}$ \\
\hline Growth period & $* * *$ & NS & NS & NS & $* *$ & NS \\
\hline Interaction & NS & NS & NS & NS & NS & NS \\
\hline
\end{tabular}

Data are means \pm SE $(n=3)$.

${ }^{2} \mathrm{P}_{\mathrm{n}}=$ net photosynthetic rate; $g_{\mathrm{S}}=$ stomatal conductance; $\mathrm{C}_{\mathrm{i}}=$ intercellular $\mathrm{CO}_{2}$ concentration; $\mathrm{F}_{\mathrm{v}} / \mathrm{F}_{\mathrm{m}}=$ maximal quantum yield of PSII photochemistry; $A_{q e}=$ apparent quantum yield; $L C P=$ light compensation point.

${ }^{y}$ Values estimated from photosynthetic light-response curves.

${ }^{\mathrm{x}} \mathrm{L}=$ linear regression; $\mathrm{NS}=$ nonsignificant; ${ }^{*} 0.01<P \leq 0.05 ; * * 0.001<P \leq 0.01 ; * * * P \leq 0.001$.
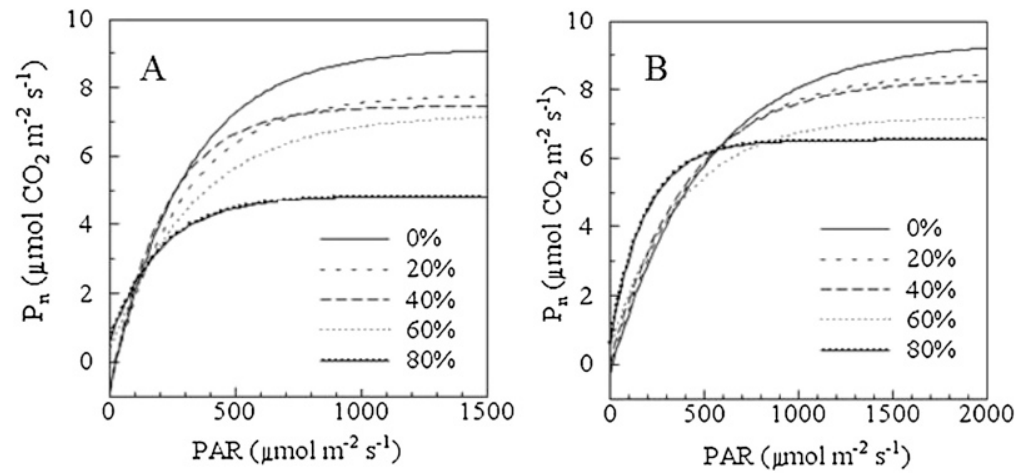

Fig. 3. The light-response curves of the photosynthesis rates of weeping fig grown under different shading levels in relation to the growth period: (A) GP I and (B) GP II. Light-response curves were determined for six pots (two per replication) at each shading level.

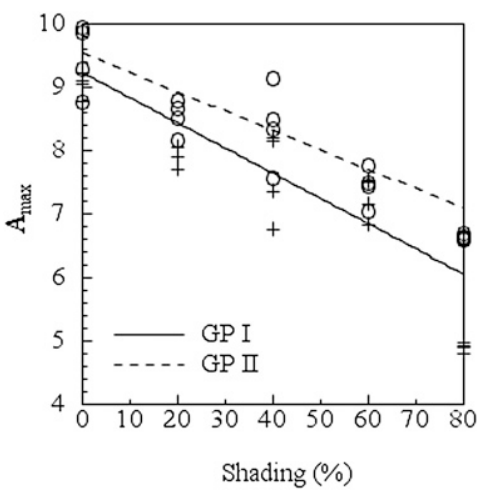

Fig. 4. Interaction effects of the shading level and growth period on the light-saturated rate of photosynthesis $\left(A_{\max }\right)$.

were higher in GP I than GP II. The light compensation point $(L C P)$ showed a significant reduction from 17.31 to 5.89 when the shading level increased (Table 1).

Plant and leaf characteristics. The exposure of the weeping fig plants to increasing shading levels resulted in a linear reduction of the stem diameter from $1.47 \mathrm{~cm}$ to $1.15 \mathrm{~cm}$ (Table 2). The environmental conditions of
GP II also resulted in a significant decrease of the stem diameter $(-17 \%)$. Significant interactions were also observed for the internode length and branch insertion angle. The internode length showed a linear increase as the shading increased during the first period, whereas there was no relationship in the second growth period (Fig. 5A). The branch insertion angle also increased linearly, but the slope was more accentuated in GP I with a relative variation of $\approx 44 \%$ being observed than GP II (+31\%) (Fig. 5B).

The leaf number showed a linear decrease resulting from the reduction of the irradiance availability (Table 2). For the mean of the two growth periods, the leaf number ranged from 1031 for the control to 557 for the $80 \%$ shaded plants. The greatest leaf number was observed in the plants grown during GP I; the total leaf area also showed the highest values in GP I but was unaffected by the shading conditions (Table 2). In contrast, the unit leaf area and specific leaf area (SLA) showed a linear increase with the shading level; these increases were $\approx 72 \%$ from the $0 \%$ to $80 \%$ of shading levels (Table 3), and these parameters were affected by the growth period with the highest value in GP II. The lamina angle showed a linear increase from $110^{\circ}$ for the control plants to $156^{\circ}$ for the $80 \%$ shaded plants. A similar pattern was found for the lamina bend radius with values in the most shaded plants being $140 \%$ greater than the control; for the mean of the shading treatments, the greatest values were found in the plants grown in GP I, whereas a significantly large lamina angle was associated with GP II (Table 3). The leaf chlorophyll content increased linearly with the shading, ranging from $46.5 \mu \mathrm{g} \cdot \mathrm{cm}^{-2}$ for the control to $65.5 \mu \mathrm{g} \cdot \mathrm{cm}^{-2}$ for the most shaded plants; the parameter was unaffected by the growth period (Table 3 ).

The plants showed a linear decrease of the total leaf thickness as the shading level increased (Table 3 ). This variation was the result of the reduction of the thickness of both the palisade $(-23 \%)$ and the spongy parenchyma $(-21 \%)$ tissues. The leaf anatomical characteristics were unaffected by the growth period.

\section{Discussion}

The increase of the shading level significantly decreased the growth of weeping fig with different effects in relation to the growth period. This result could be attributed to the greater reduction of the irradiance, as produced by the shading nets, found in GP I with respect to GP II. However, for both of the growth periods, the relative reduction of the total dry weight resulting from shading was different from that found by other authors. In summer-grown weeping fig, Fails et al. (1982a) found a relative decrease of $\approx 37 \%$ from $0 \%$ to $75 \%$ irradiance reduction, and Sarracino et al. (1992) showed a higher variation than our results in plants grown in the fall to winter period $(-63 \%)$ with the shading levels ranging from $0 \%$ to $92 \%$. This difference could be explained by the different and not comparable experimental conditions of the studies, thereby highlighting the significance of comparing the different climatic conditions for the same experiment. Moreover, our results demonstrated that the temperature affected the growth of weeping fig more than shading: the total dry weight of the $80 \%$ shaded plants grown in GP I was similar 
to that of the unshaded or less shaded $(20 \%$ and $40 \%$ ) plants during GP II. According to Mortensen (1992a), the growth of some ornamental foliage species are stimulated by temperatures up to $24{ }^{\circ} \mathrm{C}$ also at low irradiance availability. The root growth was more affected by the shading than the shoots in accordance with Brouwer (1962), who observed that at a low irradiance, the shoots (and, in particular, leaves) retain more of the limiting amount of photosynthate, leaving less carbon available for root growth. This finding was also found by Veneklaas and Poorter (1998) for the growth of tropical trees at different $P P F$ levels. However, these variations were more evident in the growth period characterized by the highest irradiance (GP I). A possible explanation of this result is

the influence of the auxins produced under conditions of higher irradiance that could stimulate the root growth, as previously found by Fini et al. (2010) in Photinia $\times$ fraseri.

As the shading level increased, the net rate of photosynthesis showed a lower reduction than the total DW production. This result shows an improved light-use efficiency of the shaded plants at the end of the growth period, as previously found by some authors (Fini et al., 2010; Miralles et al., 2011; Niinemets, 2010). The improvement of the light-use efficiency was in part confirmed by the rise of the $\mathrm{F}_{\mathrm{v}} / \mathrm{F}_{\mathrm{m}}$ ratio at the increased shading, reflecting the potential quantum efficiency of PSII, which is used as a sensitive indicator of the plant photosynthetic performance. The values found in the more shaded

Table 2. Mean effects of shading levels and growth periods on canopy characteristics of weeping fig plants.

\begin{tabular}{lccc}
\hline Treatments & Stem diameter $(\mathrm{cm})$ & Leaf $($ no./plant $)$ & Total leaf area $\left(\mathrm{cm}^{2}\right)$ \\
\hline Shading & $1.47 \pm 0.05$ & $1031 \pm 110$ & $5308 \pm 203$ \\
$0 \%$ & $1.46 \pm 0.08$ & $955 \pm 107$ & $5139 \pm 227$ \\
$20 \%$ & $1.44 \pm 0.07$ & $859 \pm 106$ & $5189 \pm 245$ \\
$40 \%$ & $1.33 \pm 0.06$ & $742 \pm 95$ & $5302 \pm 416$ \\
$60 \%$ & $1.15 \pm 0.09$ & $557 \pm 74$ & $4927 \pm 343$ \\
$80 \%$ & & & \\
Growth period & $1.50 \pm 0.05$ & $1077 \pm 49$ & $5628 \pm 129$ \\
I & $1.24 \pm 0.03$ & $581 \pm 37$ & $4718 \pm 170$ \\
II & & & \\
Significance & $\mathrm{L}^{* *}$ & $\mathrm{~L}^{* * *}$ & NS \\
Shading & $* * *$ & $* * *$ & NS \\
Growth period & $\mathrm{NS}$ & $\mathrm{NS}$ & \\
Interaction & & & \\
\hline
\end{tabular}

Data are means \pm SE $(n=3)$.

${ }^{\mathrm{z}} \mathrm{L}=$ linear regression; $\mathrm{NS}=$ nonsignificant; $* 0.01<P \leq 0.05 ; * * 0.001<P \leq 0.01 ; * * * P \leq 0.001$.
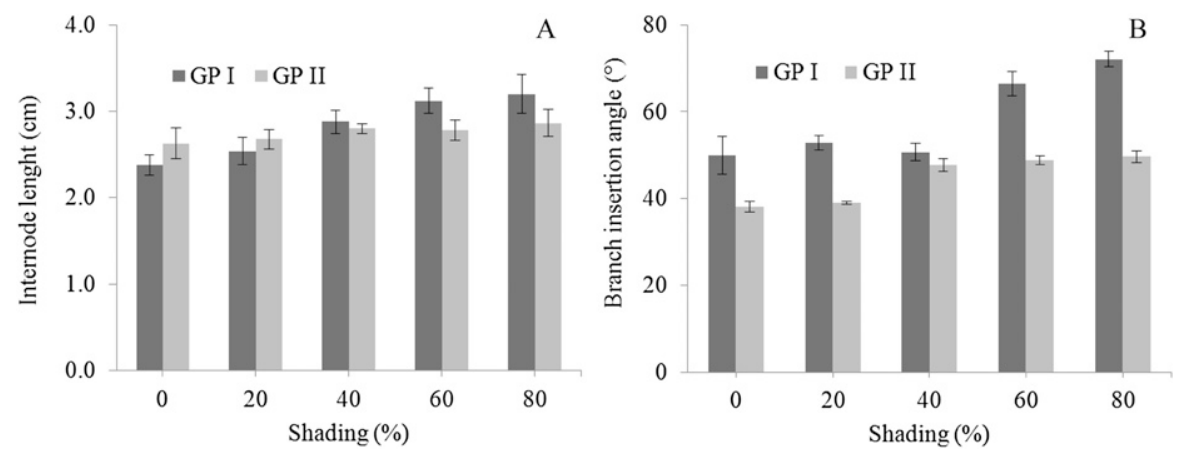

Fig. 5. Interaction effects of the shading level and growth period on the internode length $(\mathbf{A})$ and branch insertion angle $(\mathbf{B})$. The vertical bars indicate \pm SE of the mean $(n=3)$. leaves are similar to the optimal values of $\approx 0.83$ proposed by Maxwell and Johnson (2000) and was in agreement with what found by Sarijeva et al. (2007) in the leaves of ginkgo grown under shaded conditions.

The other photosynthetic parameters were also affected by the shading levels. The increase of the $C_{i}$ from 206 to $252 \mathrm{~cm}^{3} \cdot \mathrm{m}^{-3}$ with the increase in the shading level and the unaffected $g_{\mathrm{S}}$ indicate that photosynthesis at the low irradiance was not reduced by stomatal limitations (Li et al., 2009).

The quality of weeping fig could also be considered as an adaptation to the low light that is typical of an interior environment. According to Fails et al. (1982b), shadegrown weeping fig leaves had a photosynthetic advantage over sun-grown leaves at low $P P F$ levels, whereas the sun-grown leaves assumed a competitive advantage at a high irradiance. In fact, the increase of shade resulted in a reduction in the light-saturated photosynthesis $\left(A_{\max }\right)$. According to Liao et al. (2005), plants grown for a long time at a low irradiance had lesser contents of electron transfer components and photosynthetic enzymes in comparison with those grown at a high irradiance. This result could also explain the more pronounced reduction of the parameter during GP I. However, the apparent quantum yield $\left(A_{q e}\right)$ was significantly higher in the more shaded plants. Indeed, the reduction of the $A_{\max }$ in the more shaded plants was compensated by the highest light-capture surface per unit of DW (SLA), which represents an important physiological modification in the shaded plants to intercept the low irradiances better (Poorter and Nagel, 2000). Fails et al. (1982b) suggested that a low $L C P$ also could explain the better use efficiency of plants grown at low irradiances. The $L C P$ showed significant differences in our experiment with a reduction as the light increased, which was in accordance with the results of other authors for Ficus benjamina (Chen et al., 2005b).

According to Fails et al. (1982a), the light response of weeping fig plants is related to the modification of the leaf morphology and anatomy. Indeed, the leaf structure is modified by light and may contribute to the photosynthetic advantage found for shaded

Table 3. Mean effects of the shading level and growth period on the leaf characteristics of weeping fig plants.

\begin{tabular}{|c|c|c|c|c|c|c|c|c|}
\hline \multirow[b]{2}{*}{ Treatments } & \multirow{2}{*}{$\begin{array}{l}\text { Unit leaf } \\
\text { area }\left(\mathrm{cm}^{2}\right)\end{array}$} & \multirow{2}{*}{$\begin{array}{c}\text { Specific leaf } \\
\text { area }\left(\mathrm{cm}^{2} \cdot \mathrm{g}^{-1}\right)\end{array}$} & \multirow{2}{*}{$\begin{array}{l}\text { Lamina } \\
\text { angle }\left({ }^{\circ}\right)\end{array}$} & \multirow{2}{*}{$\begin{array}{l}\text { Lamina bend } \\
\text { radius }(\mathrm{cm})\end{array}$} & \multirow{2}{*}{$\begin{array}{c}\text { Chlorophyll } \\
\text { content }\left(\mu \mathrm{g} \cdot \mathrm{cm}^{-2}\right)\end{array}$} & \multicolumn{3}{|c|}{ Thickness $(\mu \mathrm{m})$} \\
\hline & & & & & & Total & Palisade & Spongy \\
\hline \multicolumn{9}{|l|}{ Shading } \\
\hline $0 \%$ & $5.57 \pm 0.50$ & $80.1 \pm 9.1$ & $110 \pm 2.6$ & $9.86 \pm 0.43$ & $46.5 \pm 2.3$ & $270 \pm 8.7$ & $80 \pm 3.3$ & $128 \pm 6.2$ \\
\hline $40 \%$ & $6.66 \pm 0.66$ & $93.3 \pm 9.4$ & $132 \pm 1.6$ & $14.23 \pm 0.74$ & $50.9 \pm 2.8$ & $235 \pm 2.7$ & $72 \pm 2.2$ & $118 \pm 3.6$ \\
\hline $60 \%$ & $7.60 \pm 0.63$ & $103.4 \pm 9.3$ & $147 \pm 1.1$ & $18.31 \pm 0.81$ & $58.8 \pm 1.8$ & $228 \pm 4.7$ & $66 \pm 3.0$ & $110 \pm 2.9$ \\
\hline $80 \%$ & $9.60 \pm 0.73$ & $137.6 \pm 9.0$ & $156 \pm 0.6$ & $23.69 \pm 0.45$ & $65.5 \pm 1.8$ & $227 \pm 2.9$ & $61 \pm 1.9$ & $100 \pm 2.8$ \\
\hline \multicolumn{9}{|l|}{ Growth period } \\
\hline \multicolumn{9}{|l|}{ Significance $^{\mathrm{z}}$} \\
\hline Shading & $\mathrm{L}^{* * *}$ & $\mathrm{~L}^{* *}$ & $\mathrm{~L}^{* * *}$ & $\mathrm{~L}^{* * *}$ & $\mathrm{~L}^{* * *}$ & $\mathrm{~L}^{* * *}$ & $\mathrm{~L}^{* * *}$ & $\mathrm{~L}^{* * *}$ \\
\hline Growth period & $* * *$ & $* * *$ & $* * *$ & $* * *$ & NS & NS & NS & NS \\
\hline Interaction & NS & NS & NS & NS & NS & NS & NS & NS \\
\hline
\end{tabular}

Data are means \pm SE $(n=3)$.

${ }^{\mathrm{z}} \mathrm{L}=$ linear regression; $\mathrm{NS}=$ nonsignificant; $* 0.01<P \leq 0.05 ; * * 0.001<P \leq 0.01 ; * * * P \leq 0.001$. 
leaves in low light. Although the shading reduced the leaf number, the increase in the unit leaf area and SLA allowed the plants to benefit from a greater surface for the light interception with a reduction in the leaf thickness. This finding was confirmed by the leaf anatomical observations showing that the reduction in the parenchyma thickness resulting from shading led to a better light penetration to the chloroplasts (Evans, 1999). In addition, the horizontal leaf orientation of the more shaded plants, as determined by the higher values of the leaf lamina angle and bend, could be considered an important characteristic that determines the improvement of light interception (Knapp and Smith, 1997). The lower light intensity in GP II determined an increase of the unit leaf area and lamina angle to improve light interception (Fitter and Hay, 1987).

The morphological modifications for light acclimatization could modify the visual quality of the plants that is defined by attributes based on the plant architecture and principal aerial organs (Boumaza et al., 2010). In particular, the visual quality of weeping fig could be related to canopy characteristics (e.g., compactness) and/or leaf characteristics (e.g., greenness) (Dijkshoorn-Dekker, 2002; Wang et al., 2005). In our study, the shading resulted in an open habitus of the plants, as indicated by the modification of the internode length and/or branch insertion angle. However, these variations were different in relation to the growth period. In particular, the internodes of the more shaded plants were longer than the unshaded plants only in GP I. One interpretation of this result is that the low mean values of light and temperature during GP II, limiting the growth, caused less internode elongation (Assmann, 1992). This result was also found by Kubatsch et al. (2005) in Ficus benjamina with shorter internodes in the plants grown at a suboptimal temperature $\left(15^{\circ} \mathrm{C}\right)$ during the acclimatization process to low light. In contrast, the branch insertion angle increased with the shading in both of the growth periods with the highest values for GP I. Moreover, the shading resulted in a thin stem, as demonstrated by the more accentuated reduction of the diameter, a result that was observed by Miralles et al. (2011) in Rhamnus alaternus, suggesting that the branch was a low priority sink for photosynthates when compared with the foliage. The modifications of the canopy architecture resulting from the increase of branch insertion angle caused a reduction of the plant compactness, more evident in GP I than in GP II, and thus should compromise the appearance of the plants (Miralles et al., 2011). In weeping fig (Fails et al., 1982a) and Rhamnus alaternus (Miralles at al., 2011), the reduction in the compactness of the canopy under low light conditions was related to the lower number of the leaves that determined a decline of the plant leaf area. In our experiment, total leaf area of shaded plants was similar to the control because the reduction of leaf number was associated with the increase of unit leaf area. This modification represents an important parameter that influences positively the foliage plant appearance (DijlshoornDekker and Eveleens-Clark, 1999).

According to Mendes et al. (2001), the increase in the chlorophyll content in more shaded plants could been interpreted as an adjustment to low-light regimes. However, this result could influence the plant quality. Indeed, Wang et al. (2005) demonstrated that the chlorophyll concentration is directly related to the degree of leaf greenness, which represents another important parameter in determining the quality and marketability of the plants at the end of production (DijlshoornDekker and Eveleens-Clark, 1999).

The climatic conditions in GP I influenced positively certain canopy characteristics (stem diameter, leaf number, and plant leaf area) and then could improve the visual quality of the plants. These modifications are related to the positive effects of the higher mean light intensity and temperature in GP I than GP II on the growth of weeping fig (DijkshoornDekker, 2002; Mortensen, 1992a).

In conclusion, the shading significantly influenced the growth and quality of weeping fig with certain differences according to the climatic conditions. The quality, in terms of the adaptation to indoor conditions and leaf characteristics, was similarly improved by the increased shading under the two growth conditions. However, the highest decrease in irradiance $(60 \%$ and $80 \%$ shading) reduced the plant growth and compactness more notably in the growth period characterized by the highest values of global radiation and temperature.

\section{Literature Cited}

Assmann, S.M. 1992. Effects of light quantity and quality during development on the morphology and stomata physiology of Commelina communis. Oecologia 92:188-195.

Boumaza, R., L. Huché-Thélier, S. DemotesMainard, E. Le Coz, N. Leduc, S. PelleschiTravier, E.M. Qannari, S. Sakr, P. Santagostini, R. Symoneaux, and V. Guérin. 2010. Sensory profiles and preference analysis in ornamental horticulture: The case of the rosebush. Food Qual. Pref. 21:987-997.

Brouwer, R. 1962. Nutritive influences on the distribution of dry matter in the plant. Neth. J. Agr. Sci. 10:361-376.

Camejo, D., P. Rodrìguez, M.A. Morales, J. Dell'Amico, A. Torecillas, and J.J. Alarcòn. 2005. High temperature effects on photosynthetic activity of two tomato cultivars with different heat susceptibility. J. Plant Physiol. 162:281-289

Cannell, M.G.R., R. Milne, L.J. Sheppard, and M.H. Unsworth. 1987. Radiation interception and productivity of willow. J. Appl. Ecol. 24:261-268.

Chen, J., D.B. McConnel, R.J. Henny, and D.J. Norman. 2005a. The foliage plant industry. Hort. Rev. 31:45-110.

Chen, J., Q. Wang, R.J. Henny, and D.B. McConnell. $2005 \mathrm{~b}$. Response of tropical foliage plants to interior low light conditions. Acta Hort. 669:51-56.

Conover, C.A. and R.T. Poole. 1990. Effects of cultural practice on acclimatization of Ficus benjamina L. J. Amer. Soc. Hort. Sci. 102:529531.
Dijkshoorn-Dekker, M.W.C. 2002. Crop quality control system: A tool to control the visual quality of pot plants. $\mathrm{PhD}$ diss., Wageningen University, Wageningen, The Netherlands.

Dijlshoorn-Dekker, M.W.C. and B.A. EveleensClark. 1999. Introduction of a market oriented information system for growth control of Ficus benjamina. Acta Hort. 507:99-105.

Evans, J.R. 1999. Leaf anatomy enables more equal access to light and $\mathrm{CO}_{2}$ between chloroplast. New Phytol. 143:93-104.

Fails, B.S., A.J. Lewis, and J.A. Barden. 1982a. Anatomy and morphology of sun- and shadegrown Ficus benjamina. J. Amer. Soc. Hort. Sci. 107:754-757.

Fails, B.S., A.J. Lewis, and J.A. Barden. 1982b. Net photosynthesis and transpiration of sun- and shade-grown Ficus benjamina leaves. J. Amer. Soc. Hort. Sci. 107:758-761.

Fini, A., F. Ferrini, P. Frangi, G. Amoroso, and C. Giordano. 2010. Growth, leaf gas exchange and leaf anatomy of three ornamental shrubs grown under different light intensities. Europ. J. Hort. Sci. 75:111-117.

Fitter, H. and R.K.M. Hay. 1987. Environmental physiology of plants. Academic Press, San Diego, CA.

Heuvelink, E., P. Tijskens, and M.Z. Kang. 2004. Modeling product quality in horticulture: An overview. Acta Hort. 654:19-30.

Knapp, A.K. and D.L. Smith. 1997. Leaf angle, light interception and water relation. Demonstrating how plants cope with multiple resource limitations in the field. Amer. Biol. Teach. 59:365-368.

Kubatsch, A., H. Grüneberg, and C. Ulrichs. 2005. Acclimatization of Ficus benjamina to temperature and irradiance conditions in indoor landscapes. J. Appl. Bot. Food Qual. 79:117-121.

Lambers, H., F.S. Chapin, III, and T.L. Pons. 1998. Plant physiological ecology. Springer-Verlag, New York, NY.

Li, X., Y. Dai, and S. Chen. 2009. Growth and physiological characteristics of Fritillaria cirrhosa in response to high irradiance and shade in age-related growth phases. Environ. Exp. Bot. 67:77-83.

Liao, J.X., Y. Ge, C.C. Huang, J. Zhang, Q.X. Liu, and J. Chang. 2005. Effects of irradiance on photosynthetic characteristics and growth of Mosla chinensis and M. scabra. Photosynthetica 43:111-115.

Maxwell, K. and G.N. Johnson. 2000. Chlorophyll fluorescence: A practical guide. J. Expt. Bot. 51:659-668.

Mendes, M.M., L.C. Gazarini, and M.L. Rodrigues. 2001. Acclimation of Myrtus communis to contrasting Mediterranean light environmentsEffects on structure and chemical composition of foliage and plant water relations. Environ. Exp. Bot. 45:165-178.

Miralles, J., J.J. Martínes-Sánchez, J.A. Franco, and S. Bañón. 2011. Rhamnus alaternus growth under four simulated shade environments: Morphological, anatomical and physiological responses. Sci. Hort. 127:562-570.

Moran, R. and D. Porath. 1980. Chlorophyl determination in intact tissues using N,Ndimethylformamide. Plant Physiol. 65:478479.

Mortensen, L.V. 1992a. Growth responses of three foliage plant species to temperature and photon flux density. Sci. Hort. 49:159-166.

Mortensen, L.V. 1992b. Diurnal photosynthesis and transpiration of Ficus benjamina L. as affected by length of photoperiod, $\mathrm{CO}_{2}$ concentration and light level. Acta Agr. Scand., Sect. B. Soil and Plant Sci. 42:100-105. 
Niinemets, Ü. 2010. A review of light interception in plant stands from leaf to canopy in different plant functional types and in species with varying shade tolerance. Ecol. Res. 25:693-714.

Peek, M.S., E. Russek-Cohen, D.A. Wait, and I.N. Forseth. 2002. Physiological response curve analysis using non linear mixed models. Oecologia 132:175-180.

Poorter, H. and O.W. Nagel. 2000. The role of biomass allocation in the growth response of plants to different levels of light, $\mathrm{CO}_{2}$ nutrients and water: A quantitative review. Aust. J. Plant Physiol. 27:595-607.

Sarijeva, G., M. Knapp, and H.K. Lichtenthaler. 2007. Differences in photosynthetic activity, chlorophyll and carotenoid levels, and in chlorophyll fluorescence parameters in green sun and shade leaves of Ginkgo and Fagus. J. Plant Physiol. 164:950-955.

Sarracino, J.M., R. Merritt, and C.K. Chin. 1992. Morphological and physiological characteristics of Leea coccinia and Leea rubra in response to light flux. HortScience 27:400403.

Sawwan, J.S. and R.S. Ghunem. 1999. Light acclimatization of Schefflera arboricola. Adv. Hort. Sci. 13:151-155.

Schreiber, U., U. Schliwa, and W. Bilger. 1986. Continuous recording of photochemical and non-photochemical chlorophyll fluorescence quenching with a new type of modulation fluorometer. Photosynth. Res. 10:51-62.

Scuderi, D., A. Li Rosi, C. Cassaniti, A. Paratore, and D. Romano. 2008. The influence of shading levels on foliage plant growth and quality. Acta Hort. 801:1191-1196.

Valladares, F. and R.W. Pearcy. 2000. The role of crown architecture for light harvesting and carbon gain in extreme light environments assessed with a realistic 3-D model. Anal. Jard. Bot. Madrid 58:3-16.

Vats, S.K., S. Pandey, and P.K. Nagar. 2002. Photosynthetic response to irradiance in Valeriana jatamansi Jones, a threatened under-storey medicinal herb of Western Himalaya. Photosynthetica 40:625-628.

Veneklaas, E.J. and L. Poorter. 1998. Growth and carbon partitioning of tropical tree seedling in contrasting light environments, p. 337-361. Lambers, H., H. Poorter, and M.M.I. Van Vuuren (eds.). Inherent variation in plant growth. Physiological mechanisms and ecological consequences. Backhuys Publishers, Leiden, The Netherlands.

Veneklaas, E.J., M.P.R.M. Santos Silva, and F. den Ouden. 2002. Determinants of growth rate in Ficus benjamina L. compared to related fastergrowing woody and herbaceous species. Sci. Hort. 93:75-84.

Wang, Q., J. Chen, R.H. Stamps, and Y. Li. 2005 Correlation of visual quality grading and SPAD reading of green-leaved foliage plants. J. Plant Nutr. 28:1215-1225.

Yeh, D.M. and H.M. Wang. 2000. Effects of irradiance on growth, net photosynthesis and indoor performance of the shade-adapted plant, maidenhair fern. J. Hort. Sci. Biotechnol. 75:293-298. 